\title{
Characterization of the theta-type plasmid pCD3.4 from Carnobacterium divergens, and modulation of its host range by RepA mutation
}

\begin{abstract}
Correspondence
Michael E. Stiles

michael.stiles@telusplanet.net
\end{abstract}

Received 23 June 2005

Revised 22 August 2005

Accepted 20 September 2005

\author{
Marco J. van Belkum† and Michael E. Stilesł \\ Department of Agricultural, Food and Nutritional Science, University of Alberta, Edmonton, \\ Alberta, Canada T6G 2P5
}

\begin{abstract}
The complete nucleotide sequence of the 3475 bp plasmid pCD3.4 from Carnobacterium divergens LV13, which encodes the bacteriocin divergicin A, was determined. Nucleotide sequence, deletion and complementation analyses revealed the presence of a trans-acting replication protein, RepA, and DNA sequences involved in plasmid replication and copy-number control. The DNA region preceding the $r e p A$ gene probably contains the origin of replication. This sequence includes four and a half direct repeats (iterons) of $22 \mathrm{bp}$, to which RepA is thought to bind, and an AT-rich region containing a 12 bp repeat, at which initiation of DNA might occur. Further upstream of this sequence resides a fifth iteron required for optimal plasmid replication. The RepA protein shows homology to replication proteins of the pUCL287 subfamily of theta-type replicons. Two ORFs were found downstream of the repA gene that could be deleted without affecting replication and stability of the plasmid. pCD3.4 has a narrow host range, and could only be maintained in Carnobacterium spp.; however, a mutant of the plasmid was obtained that enabled the pCD3.4 replicon to replicate in Enterococcus faecium, but not in Carnobacterium spp. The mutation was located in the C-terminal region of the RepA protein, changing a proline into a serine. This is believed to be the first example of such plasmid-host-range modulation in Gram-positive bacteria.
\end{abstract}

\section{INTRODUCTION}

Plasmids from lactic acid bacteria (LAB) have received considerable attention because they often contain important traits for fermentation, as well as genetic information for phage resistance and bacteriocin production. Furthermore, plasmids from a variety of LAB, especially from lactococci, have been characterized with the purpose of constructing cloning vectors to enhance the properties of LAB. Most of the small plasmids from $L A B$ that are used as cloning vectors have rolling-circle-type replication. However, the structural and segregational instability of these plasmids for cloning DNA is well known (Kiewiet et al., 1993b). In addition, the promiscuity of many rolling-circle replicating plasmids has made them relatively unsuitable for use as 'food-grade' cloning vectors in LAB. Therefore, the characterization of

†Present address: Department of Chemistry, University of Alberta, Edmonton, Alberta, Canada T6G 2 G2.

$\ddagger$ Present address: CanBiocin Inc., 1015, 8308-114 Street, Edmonton, Alberta, Canada T6G 2E1.

Abbreviations: $L A B$, lactic acid bacteria; ssDNA, single-stranded DNA. The GenBank/EMBL/DDBJ accession number for the pCD3.4 nucleotide sequence reported in this paper is D0087597. the more stable theta-type replicating plasmids from $\mathrm{LAB}$ has received more attention.

Based on the mechanism of initiation of DNA replication in plasmid genomes, at least five classes of theta replicons have been identified (Bruand et al., 1993; Meijer et al., 1995). Class A plasmids depend on the presence of a plasmidencoded replication protein (Rep). The host-encoded DNA polymerase I (PolI) is not required for replication of these plasmids. In addition to the rep gene, the replicon consists of an origin of replication (ori) that contains DNA iterons recognized by Rep, and an AT-rich region that generally contains repeats, as well as binding site(s), for the hostencoded DnaA proteins. Examples of class A plasmids in Gram-positive bacteria are pUCL22 (Frère et al., 1993), pWVO2 (Kiewiet et al., 1993a) and pCI305 (Hayes et al., 1991), all of which are found in lactococci, and pLA103 from Lactobacillus acidophilus (Kanatani et al., 1995) and pUCL287 from Tetragenococcus halophilus (Benachour et al., 1997). Plasmids pSC101 and P1 from Escherichia coli are well-known examples of class A plasmids in Gram-negative bacteria (Abeles et al., 1984; Churchward et al., 1983). The broad-host-range streptococcal plasmids pAM $\beta 1$ (Bruand et al., 1993) and pIP501 (Le Chatelier et al., 1993) have been classified as class D plasmids. These plasmids require not 
only a Rep protein, but also Poll for replication. A novel type of replicon has been described for the Bacillus subtilis plasmid pLS20 (Class E, Meijer et al., 1995); its minimal replicon does not contain an ORF, and it replicates in a PolImutated strain. Plasmid p256 from Lactobacillus plantarum was the first Rep-independent LAB plasmid to be identified (Sørvig et al., 2005). An additional group of thetareplicating plasmids has DNA iterons within the coding sequence of the replication initiator protein, and members of this group are PolI-independent. Plasmid pLS32 (Tanaka \& Ogura, 1998) of Bacillus natto, the enterococcal plasmids pAD1 (Weaver et al., 1993), pCF10 (Hedberg et al., 1996) and pPD1 (Fujimoto et al., 1995), and the lactococcal plasmid pCI2000 (Kearney et al., 2000), are examples of this family; however, this group of plasmids might be related to class A replicons (Kearney et al., 2000).
To date, no plasmids from Carnobacterium spp. have been fully characterized. The production of the antibacterial peptide divergicin A from Carnobacterium divergens LV13 has been linked to the $3.4 \mathrm{~kb}$ plasmid $\mathrm{pCD} 3.4$, and its structural and immunity genes have been cloned and sequenced (Worobo et al., 1995). This paper describes the entire nucleotide sequence of pCD3.4. Here, we report on the genetic identification of elements involved in pCD3.4 replication, and show that its replicon is of Class $\mathrm{A}$, and that its narrow host range is influenced by the Rep protein. A possible explanation for this host-range modulation is discussed.

\section{METHODS}

Bacterial strains, plasmids and media. The bacterial strains and plasmids used in this study are listed in Table 1. E. coli was grown

Table 1. Bacterial strains and plasmids

\begin{tabular}{|c|c|c|}
\hline Strain or plasmid & Description & Reference or source \\
\hline \multicolumn{3}{|l|}{ Strains } \\
\hline E. coli $\mathrm{MH} 1$ & MC1061 derivative; araD139 lacX74 galU galK hsr hsm1 strA & Casadaban \& Cohen (1980) \\
\hline E. coli $\mathrm{BL} 21(\mathrm{DE} 3)$ & $\mathrm{F}^{-} o m p T h s d S_{\mathrm{B}}\left(\mathrm{r}_{\mathrm{B}}^{-} \mathrm{m}_{\mathrm{B}}^{-}\right) g a l d c m(\mathrm{DE} 3)$ & Studier \& Moffat (1986) \\
\hline C. divergens $\mathrm{LV} 13$ & & Worobo et al. (1995) \\
\hline C. maltaromaticum UAL26 & & Laboratory collection \\
\hline C. maltaromaticum $\mathrm{LV} 17 \mathrm{C}$ & & Ahn \& Stiles (1990) \\
\hline Lc. lactis MG1363 & & Gasson (1983) \\
\hline Ent. faecalis ATCC 19433 & & ATCC \\
\hline Ent. faecium BFE900 & & Franz et al. (1999) \\
\hline Leu. gelidum UAL187-13 & & Hastings \& Stiles (1991) \\
\hline Lb. casei ATCC 393 & & ATCC \\
\hline \multicolumn{3}{|l|}{ Plasmids } \\
\hline pUC118 & lac $Z^{\prime}, 3 \cdot 2 \mathrm{~kb}, \mathrm{Ap}^{\mathrm{r}}$ & Vieira \& Messing (1987) \\
\hline pUC7e & pUC7 containing $1.0 \mathrm{~kb} \mathrm{Em}^{\mathrm{r}}$ gene of pE194 in PstI site, $3 \cdot 7 \mathrm{~kb}$ & $\mathrm{UofG}^{*}$ \\
\hline pGS30 & pUC7 containing $1.0 \mathrm{~kb} \mathrm{Cm}^{\mathrm{r}}$ gene of $\mathrm{pC} 194$ in Pst $\mathrm{I}$ site, $3 \cdot 7 \mathrm{~kb}$ & UofG \\
\hline pUC118e & pUC118 containing $1.0 \mathrm{~kb} \mathrm{Em}^{\mathrm{r}}$ gene, $4 \cdot 2 \mathrm{~kb}$ & This study \\
\hline pUC118-C & pUC118 containing $1.0 \mathrm{~kb} \mathrm{Cm}^{\mathrm{r}}$ gene, $4 \cdot 2 \mathrm{~kb}$ & This study \\
\hline pMG36e & $3.6 \mathrm{~kb}, \mathrm{Em}^{\mathrm{r}}$ & van de Guchte et al. (1989) \\
\hline pT713 & $2 \cdot 8 \mathrm{~kb}, \mathrm{Ap}^{\mathrm{r}}, \mathrm{T} 7$-polymerase expression vector & Tabor \& Richardson (1985) \\
\hline pTCD1 & pT713 containing $2 \cdot 2 \mathrm{~kb}$ Sacl-EcoRV fragment, $5 \cdot 0 \mathrm{~kb}$ & This study \\
\hline pCD3.4 & $3 \cdot 475 \mathrm{~kb}$ & Worobo et al. (1995) \\
\hline pCD5 & $3.4 \mathrm{~kb} E c o \mathrm{RV}$ fragment ligated to $1.0 \mathrm{~kb} \mathrm{Em}^{\mathrm{r}}$ gene & This study \\
\hline pCD6 & $2 \cdot 1 \mathrm{~kb} M b o \mathrm{I}$ fragment ligated to $1 \cdot 0 \mathrm{~kb} \mathrm{Em}^{\mathrm{r}}$ gene & This study \\
\hline pCD12 & $1.0 \mathrm{~kb} H$ in $\mathrm{PI}-A v a \mathrm{II}$ fragment ligated to $1.0 \mathrm{~kb} \mathrm{Em}^{\mathrm{r}}$ gene & This study \\
\hline pCD14 & pMG36e containing $0.7 \mathrm{~kb}$ repA gene, $4.3 \mathrm{~kb}$ & This study \\
\hline pCD15 & pUC118-C containing $1.5 \mathrm{~kb} M b o \mathrm{I}-E c o \mathrm{RI}$ fragment, $5.7 \mathrm{~kb}$ & This study \\
\hline pCD16 & $2 \cdot 0 \mathrm{~kb}$ AvaII fragment ligated to $1.0 \mathrm{~kb} \mathrm{Em}^{\mathrm{r}}$ gene & This study \\
\hline pCD17 & $1.4 \mathrm{~kb}$ HindIII-AvaII fragment ligated to $1.0 \mathrm{~kb} \mathrm{Em}^{\mathrm{r}}$ gene & This study \\
\hline pCD18 & $1 \cdot 4 \mathrm{~kb} H i n \mathrm{PI}$ fragment ligated to $1.0 \mathrm{~kb} \mathrm{Em}^{\mathrm{r}}$ gene & This study \\
\hline pCD51 & pCD5 containing repA mutation, $4 \cdot 4 \mathrm{~kb}$ & This study \\
\hline pCD52 & pCD5 containing repA mutation, $4 \cdot 4 \mathrm{~kb}$ & This study \\
\hline pCD70 & pUC118e containing $1.4 \mathrm{~kb}$ HinPI fragment, $5 \cdot 6 \mathrm{~kb}$ & This study \\
\hline pCD71 & pUC118e containing $1.3 \mathrm{~kb}$ SacI-HinPI fragment, $5.5 \mathrm{~kb}$ & This study \\
\hline
\end{tabular}

${ }^{\star}$ UofG, University of Groningen, The Netherlands. 
in TY broth (Rotlander \& Trautner, 1970) at $37^{\circ} \mathrm{C}$; carnobacteria, enterococci and leuconostocs were grown in APT broth (All Purpose Tween; Difco) at 25,30 and $30^{\circ} \mathrm{C}$, respectively. Lactococcus lactis was grown in glucose-M17 broth (Terzaghi \& Sandine, 1975) at $30^{\circ} \mathrm{C}$, and lactobacilli were grown in MRS broth (De Man et al., $1960)$ at $37^{\circ} \mathrm{C}$. When appropriate, antibiotics were added to the media at the following selective concentrations: erythromycin $\left(200 \mu \mathrm{g} \mathrm{ml}^{-1}\right)$, chloramphenicol $\left(25 \mu \mathrm{g} \mathrm{ml}^{-1}\right)$ and ampicillin $\left(150 \mu \mathrm{g} \mathrm{ml}^{-1}\right)$ for E. coli; erythromycin $\left(5 \mu \mathrm{g} \mathrm{ml}^{-1}\right)$ for Carnobacterium maltaromaticum, Lactobacillus casei, Leuconostoc gelidum and Lc. lactis; chloramphenicol $\left(5 \mu \mathrm{g} \mathrm{ml}^{-1}\right)$ for C. maltaromaticum. Erythromycin was used at 50 and $150 \mu \mathrm{g} \mathrm{ml}^{-1}$ for Enterococcus faecalis and Enterococcus faecium, respectively.

DNA manipulations and transformations. Cloning and DNA manipulations were performed as described by Sambrook et al. (1989). Enzymes used for molecular cloning were obtained from Invitrogen Life Technologies, and used as specified by the manufacturer. Plasmid DNA from E. coli was isolated as described by Birnboim \& Doly (1979); with some modifications, the same method was used to isolate plasmid DNA from LAB (van Belkum \& Stiles, 1995). Nucleotide sequencing was based on the method of Sanger et al. (1977), and carried out in a Perkin-Elmer ABI-Prism DNA sequencer, with fluorescent chain terminators. Electroporation of Lc. lactis was performed as described by Holo \& Nes (1989). For transformation of other LAB, cells were grown in APT or MRS medium supplemented with $2 \%(\mathrm{w} / \mathrm{v})$ glycine. Exponentially growing cells were harvested, and washed twice with ice-cold water, and twice with ice-cold electroporation buffer $(0.5 \mathrm{M}$ sucrose, $10 \%$, v/v, glycerol, $1 \mathrm{mM} \mathrm{MgCl} 2,5 \mathrm{mM}$ potassium phosphate buffer, $\mathrm{pH}$ 6), concentrated 100 -fold in the same buffer, divided into $50 \mu \mathrm{l}$ portions, and stored at $-70^{\circ} \mathrm{C}$. Electroporation was carried out as described by van Belkum \& Stiles (1995), using a Gene-Pulser instrument (Bio-Rad). Competent E. coli cells were transformed by the method of Mandel \& Higa (1970).

Detection of single-stranded DNA. For detection of singlestranded DNA (ssDNA) in C. divergens LV13, the method described by Leenhouts et al. (1991) was used. Non-radioactive probes were made with a random-primed labelling and detection kit (Boehringer Mannheim), and used in Southern hybridization.

Construction of plasmids. Deletion derivatives of plasmid pCD3.4 were made using the erythromycin gene of pUC7e as a selection marker (Fig. 1). The $1 \mathrm{~kb}$ Bam HI fragment containing the erythromycin gene from pUC7e was isolated, treated with Klenow enzyme, and ligated into pCD3.4 that had been cut by EcoRV. The resulting plasmid, $\mathrm{pCD} 5$, contains a deletion in the promoter region of the divergicin A operon. Plasmid pCD6 was constructed by ligating pCD3.4, which had been digested with $M b o \mathrm{I}$, with the $1 \mathrm{~kb}$ BamHI fragment containing the erythromycin gene from pUC7e. Plasmids pCD12, pCD16, pCD17 and pCD18 were constructed by ligating the $1 \mathrm{~kb}$ BamHI fragment from pUC7e with pCD3.4 cut with AvaII and HinPI, AvaII, AvaII and HindIII, or HinPI, respectively, after treatment with Klenow enzyme. To investigate further the exact size of the pCD3.4 replicon, plasmids pCD70 and pCD71 were made in E. coli as follows: a $1 \mathrm{~kb}$ Sall fragment containing the erythromycin gene from pUC7e was cloned into pUC118, giving

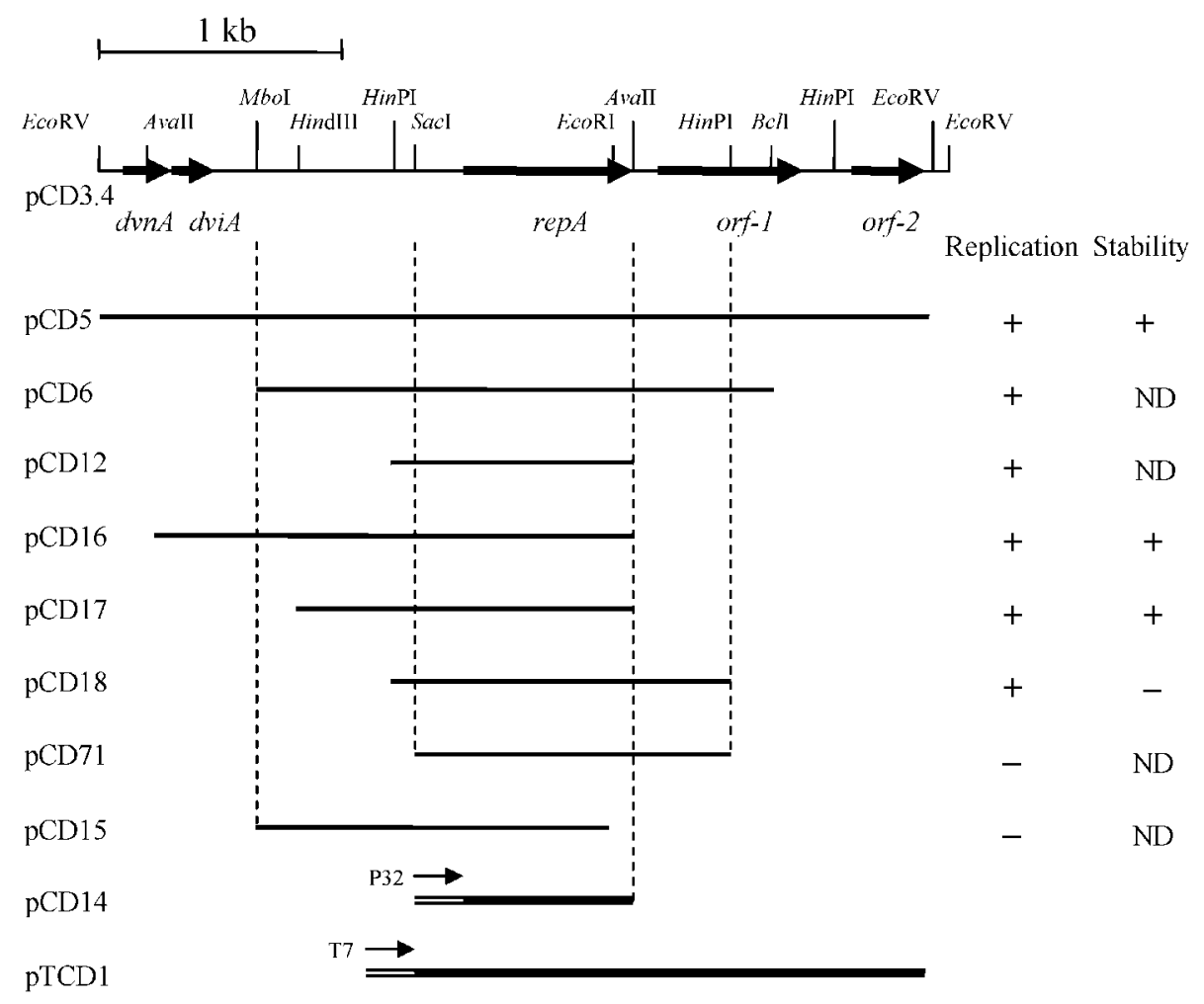

Fig. 1. Schematic representation of plasmid pCD3.4 and its subclones. The location and direction of transcription of $d v n A$, $d v i A, \operatorname{rep} A$, orf-1 and orf-2, and the positions of some restriction sites, are shown. The ability of various deletion derivatives to replicate in C. maltaromaticum UAL26, and their segregational stability, are indicated. The promoters P32 and T7, used to express some of the subclones, and the direction of their transcription, are shown. ND, Not done. 
pUC118e; the $1.4 \mathrm{~kb}$ HinPI fragment from pCD3.4 was blunt-ended by Klenow enzyme, and ligated into the SmaI site of pUC118e, resulting in plasmid pCD70; a 65 bp deletion in the pCD3.4 replicon of pCD70 was made by digesting this plasmid with SacI, followed by self-ligation of the remaining fragment, giving plasmid pCD71. Plasmids pCD14 and pCD15 were constructed for the complementation experiment with the repA gene. Using primers MB63 and MB64 containing the restriction sites $X b a \mathrm{I}$ and $K p n \mathrm{I}$ (underlined), respectively, the repA gene of pCD3.4 was amplified by PCR. The nucleotide sequences of the two primers were as follows: MB63, 5'-ATATTCTAGATGTGAGGGGAGGTCGAAA-3'; MB64, 5' -TATAGGTACCTTTTATTTCGTCCAGTCGTG-3'. The resulting PCR product was cloned into the $\mathrm{Xba \textrm {I }}$ and $\mathrm{KpnI}$ restriction sites of pMG36e, giving plasmid pCD14. Plasmid pUC118-C was constructed by cloning the $1 \mathrm{~kb}$ chloramphenicol gene of pGS30 into the SalI site of pUC118. The $1.5 \mathrm{~kb} M b o I-E c o R I$ fragment of pCD3.4 was then cloned into the BamHI and EcoRI sites of pUC118-C, resulting in plasmid pCD15. To overexpress genes of interest, plasmid pCTD1 was constructed by cloning the $2 \cdot 2 \mathrm{~kb}$ SacI-EcoRV fragment of pCD3.4 into the SacI and SmaI restriction sites of the expression vector pT713.

Plasmid stability. To investigate the segregational stability of pCD3.4 derivatives, cultures of C. maltaromaticum UAL26 containing these plasmids were first grown in APT containing erythromycin as selective pressure at $25^{\circ} \mathrm{C}$. After achieving full growth, the cultures were diluted $10^{-6}$ in non-selective medium, and grown for an additional $24 \mathrm{~h}$ until full growth (equivalent of 20 generations). The fully grown cultures were diluted again $10^{-6}$ in non-selective medium. This was repeated until the cultures had grown for 100 generations in the absence of selective pressure. To determine the percentage of cells that were resistant to the antibiotic, cells from fully grown cultures after each dilution step were plated on APT agar plates without antibiotic, and grown overnight at $25^{\circ} \mathrm{C}$. The next day, 100 colonies from each culture were stabbed onto APT agar plates with and without erythromycin, and grown for an additional $24 \mathrm{~h}$ to determine the percentage of cells that had lost the plasmid.

Overexpression of proteins in E. coli by T7 RNA polymerase. Proteins in cultures of E. coli BL21(DE3) were overexpressed, as described by van Belkum et al. (1997).

\section{RESULTS AND DISCUSSION}

\section{Nucleotide sequence analysis}

Part of plasmid pCD3.4 had previously been sequenced (coordinates 1-581), and it revealed the presence of the divergicin A operon consisting of the divergicin A structural gene $(d v n A)$, its cognate immunity gene $(d v i A)$, and a potential rho-independent terminator (Worobo et al., 1995). Plasmid pCD3.4 has now been completely sequenced, and consists of $3475 \mathrm{bp}$, with a $\mathrm{G}+\mathrm{C}$ content of $31 \cdot 3 \mathrm{~mol} \%$. Analysis of the sequence revealed the presence of three additional ORFs (Fig. 1). The first ORF, repA, could encode a protein of 238 aa that shows homology with replication proteins from the pUCL287 family of theta-type replicating plasmids, such as Rep1 from pIP1629 of Staphylococcus epidermidis (46\% identity) (Aubert et al., 1998), Rep from pS86 of Ent. faecalis (66\% identity) (Martínez-Bueno et al., 2000), RepA from pLA103 of Lactobacillus acidophilus (38\% identity) (Kanatani et al., 1995), RepA from pLKS of Lactobacillus plantarum (34\% identity) (Eguchi et al., 2000), and RepA from pUCL287 from Tetragenococcus halophilus (33\% identity) (Benachour et al., 1997). Plasmid pUCL287 replicates by a bidirectional theta mechanism, and is an example of a class A replicon (Benachour et al., 1995, 1997). A putative promoter and a RBS were located upstream of the repA gene (Fig. 2). orf-1 and orf-2 (Fig. 1) were found downstream of repA, and could encode proteins of 185 and 94 aa, respectively. RBSs precede both ORFs, but no homology was found in the database with their predicted proteins. No putative promoters were found immediately upstream of these two ORFs, indicating that orf- 1 and orf-2 might be co-expressed with repA. A putative promoter (coordinates 3454-8), with TTGGAT as the -35 region, and TATCTT as the -10 region, was located upstream of $d v n A$. Primer extension analysis of $d v n A$ confirmed the presence of this promoter structure (J. K. McCormick \& L. Saucier, unpublished data).

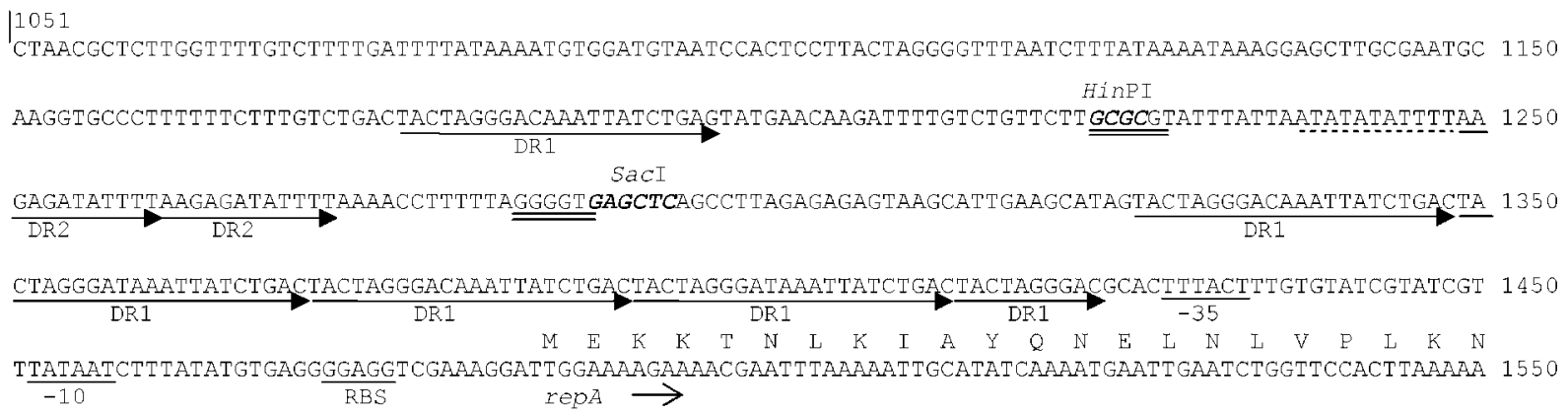

Fig. 2. Nucleotide sequence of the putative origin of replication and the $5^{\prime}$ end of repA. The deduced amino acid sequence for the N-terminal part of RepA is shown above the nucleotide sequence. The DNA iteron (DR1) and the 12 bp direct repeats (DR2) are indicated by arrows. The putative -35 and -10 promoter regions, and a possible RBS, are indicated, as well as the recognition sites for restriction enzymes HinPI and Sacl (bold italics). The GC clusters are double underlined, and a nucleotide sequence identical to the 11 bp repeats found in pS86 (Martínez-Bueno et al., 2000) is indicated by a dashed line; the sequence corresponds to nt 1051-1550 of accession no. DQ087597. 
Like many Class A replicons, two types of direct repeats were found upstream of the putative promoter sequence of repA. A $22 \mathrm{bp}$ iteron is repeated $5 \cdot 5$ times. The first (coordinates 1177-1198) and second repeats (coordinates 1327-1348) are separated by a 128 bp sequence that contains a $56 \mathrm{bp}$ AT-rich region flanked by GC clusters, and carries a $12 \mathrm{bp}$ direct repeat (coordinates 1249-1272) (Fig. 2). It is proposed that the AT-rich region is the site where the two DNA strands separate during replication initiation, and that the GC clusters act as clamps to limit melting of the strands in the direction of the direct repeats (Kim \& Meyer, 1991). A DnaA box was not found on pCD3.4, indicating that this host-encoded protein might not be involved in plasmid replication. The iterons of pS86 and pCD3.4 are very similar: 15 out of 22 nucleotides are identical, including the first three and the last nine nucleotides of the repeats (MartínezBueno et al., 2000). The fact that the Rep proteins and iterons of pS86 and pCD3.4 share significant similarity is not surprising, assuming that these replication proteins recognize and interact with the iterons to regulate plasmid replication. The two $12 \mathrm{bp}$ repeats in the AT-rich region of pCD3.4 differ from the two 11 bp repeats in pS86, although an $11 \mathrm{bp}$ sequence ( $5^{\prime}$-ATATATATTTT- $3^{\prime}$ ), identical to the $11 \mathrm{bp}$ repeats of pS86, was found adjacent to the $12 \mathrm{bp}$ repeats of pCD3.4. The significance of this finding is not known.

Several theta-type replicons, including that of pS86, contain one or more inverted repeats that overlap the promoter region of the replication gene (Benachour et al., 1997; Foley et al., 1996; Martínez-Bueno et al., 2000). In pCI305, it has been shown that the replication protein binds to the inverted repeat, probably to autoregulate its own expression (Foley et al., 1996). However, such inverted repeats were not observed in the promoter region of repA of pCD3.4, suggesting a different mechanism of regulation.

The $2 \cdot 2 \mathrm{~kb}$ SacI-EcoRV fragment of pCD3.4 containing repA, orf-1 and orf-2 was cloned behind the inducible T7 promoter of pT713, resulting in pTCD1. Cell lysates of induced or uninduced E. coli BL21(DE3) cultures containing pTCD1 were examined using Tricine SDS-PAGE. Expression of the cloned insert of pTCD1 after induction with IPTG resulted in the production of three proteins of 28,22 and $12 \mathrm{kDa}$ (Fig. 3). This result is in good agreement with the predicted molecular masses of $28.0,21.9$ and $11.5 \mathrm{kDa}$ for RepA, Orf- 1 and Orf-2, respectively, and confirms the presence of the genes encoding these proteins.

\section{Detection of SsDNA}

Whole-cell lysates of LV13 transformed with plasmid pMG36e were treated or not treated with S1 nuclease, and hybridized with pCD3.4 or pMG36e DNA, to determine whether pCD3.4 produces ssDNA, using pMG36e as a positive control; pMG36e is a derivative of the rolling-circle plasmid pWVO1 (van de Guchte et al., 1989). ssDNA was

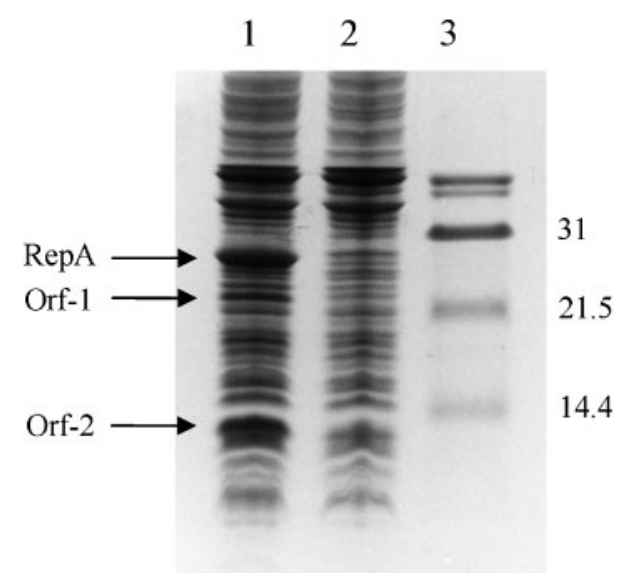

Fig. 3. Overexpression of the gene products of repA, orf-1 and orf-2 in $E$. coli by the T7 promoter. Lanes 1 and 2, lysates of $E$. coli BL21(DE3) containing pTCD1 and pT713, respectively. Lane 3, low-molecular-mass marker (Bio-Rad). The positions of RepA, Orf-1 and Orf-2 are shown on the left, and the sizes of the molecular standard $(\mathrm{kDa})$ are shown on the right.

detected from pMG36e, but not from pCD3.4 (Fig. 4), providing further evidence that pCD3.4 belongs to the theta-type family of replicons.

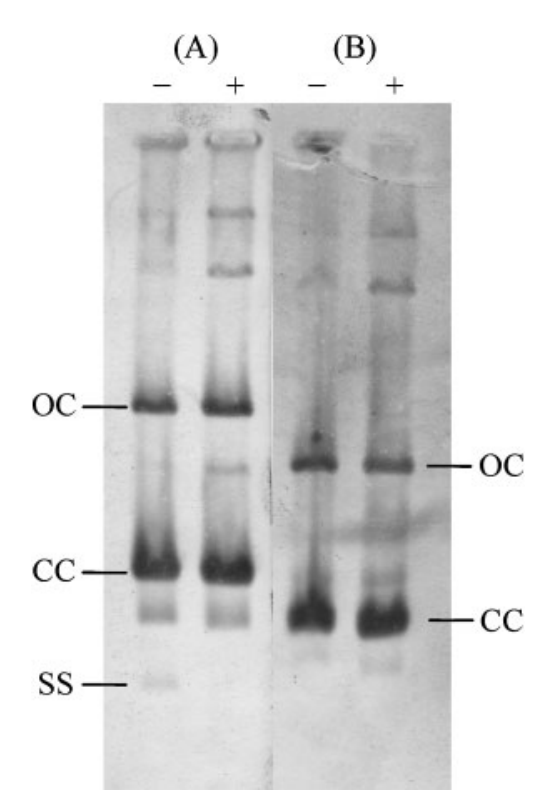

Fig. 4. Hybridization of plasmid DNA in whole-cell lysates of C. maltaromaticum LV13 containing pMG36e, using pMG36e $(\mathrm{A})$ and pCD3.4 (B) as probes. DNA from the whole-cell lysates was treated $(+)$ or not treated $(-)$ with $S 1$ nuclease. OC, CC and SS indicate the positions of open circular, covalently closed circular and single-stranded DNA, respectively. 


\section{Identification of the replication and copy- number control regions of pCD3.4}

Fragments of pCD3.4 were ligated with a $1 \mathrm{~kb}$ DNA fragment containing the erythromycin-resistance marker, and transformed into C. maltaromaticum UAL26 (Fig. 1). The results show that the smallest fragment from pCD3.4 able to transform UAL26 was a $1 \mathrm{~kb}$ HinPI-AvalI fragment in pCD12. Apparently, the only ORF on pCD3.4 required for replication is repA. Two plasmids, pCD14 and pCD15, were constructed to assess the function of RepA in replication. Plasmid pCD14 contains the repA gene cloned behind the constitutive lactococcal P32 promoter of the shuttle vector pMG36e, with erythromycin as the selection marker. In pCD15, a $1.5 \mathrm{~kb} M b o I-E c o$ RI fragment containing the putative origin of replication of $\mathrm{pCD} 3.4$, and a truncated repA gene, was cloned into the chloramphenicolencoding E. coli vector pUC118-C. Chloramphenicolresistant transformants of C. maltaromaticum UAL26 could not be obtained after electroporation with pCD15; however, when $C$. maltaromaticum UAL26 contained pCD14, this strain could be transformed with pCD15. Plasmid profile analysis showed that these transformants contained two independent plasmids (pCD14 and 15), and not a product arising from integration of $\mathrm{pCD} 14$ into pCD15 by homologous recombination at repA (data not shown). This shows that RepA complements in trans the replication of the pCD3.4 replicon.

Two plasmids were made based on pUC118e to investigate whether the 65 bp HinPI-SacI fragment, which contains the two $12 \mathrm{bp}$ repeats in the AT-rich region, is essential for replication of pCD3.4 in Carnobacterium spp. Plasmid pUC118e replicates in E. coli, but not in Carnobacterium spp. Cloning the $1 \cdot 4 \mathrm{~kb}$ HinPI fragment from pCD3.4 into pUC118e created plasmid pCD70, and plasmid pCD71 was constructed by deleting the 65 bp HinPI-SacI fragment from pCD70. Electroporation of C. maltaromaticum UAL26 with pCD70 or pCD71, and selecting for erythromycin resistance, resulted in transformants containing pCD70 only. This result indicates that the $65 \mathrm{bp}$ Hin PI-SacI segment is necessary for replication. Deletion of two of the four $11 \mathrm{bp}$ repeats in pUCL287 also abolished plasmid replication, indicating that the presence of these types of repeats is essential for replication (Benachour et al., 1997).

To search for the region required for stable maintenance of the pCD replicon, C. maltaromaticum UAL26 cells containing $\mathrm{pCD} 5, \mathrm{pCD} 16, \mathrm{pCD} 17$ or $\mathrm{pCD} 18$ were grown in the absence of erythromycin. Erythromycin resistance of $C$. maltaromaticum UAL26 transformed with pCD5, pCD16 or pCD17 was not lost after 100 generations (data not shown), indicating that orf-1, orf-2, $d v n A$ and $d v i A$ do not play a role in plasmid maintenance. However, less than $1 \%$ of UAL26 transformed with pCD18 showed erythromycin resistance after 20 generations. Plasmid DNA was not detected when plasmid DNA was isolated from cells that had lost their erythromycin resistance, indicating that the erythromycinsensitive cells had lost pCD18. Agarose gel electrophoresis of the plasmid isolated from C. maltaromaticum UAL26 containing pCD18, which was grown in the presence of the antibiotic, showed little DNA compared with cells containing pCD5, pCD16 or pCD17 (data not shown). No difference was observed in the plasmid copy number between pCD5, pCD16 and pCD17 (data not shown). These results indicate that deleting a $0 \cdot 4 \mathrm{~kb}$ HindIII-HinPI DNA region containing the first 22 bp repeat of pCD3.4 reduces the copy number, and affects the stability of the pCD replicon. It is not uncommon for theta-type plasmids to contain auxiliary iterons. The iteron is the target of the replication initiator protein, and may be important in the control of plasmid copy number. In plasmid P1, deleting these extra copies of iterons increases the copy number of the plasmid (Pal et al., 1986). In contrast, removing the region in pCD3.4 that contains the extra $22 \mathrm{bp}$ repeat actually reduces the copy number. This was confirmed by the low yield of plasmid pCD12, a plasmid that also lacks the $0 \cdot 4 \mathrm{~kb}$ HindIII-HinPI DNA region, isolated from UAL26 (data not shown). The fact that plasmids such as pS86 and pUCL287 contain one or more inverted repeats overlapping the promoter of the replication region, and that they do not seem to have auxiliary iterons, suggests that the copy number of pCD3.4 is regulated differently to these other plasmids. Further work needs to be done to show that the copy number and stability of pCD3.4 indeed depend on this auxiliary iteron, and not on something else that is located on this $0 \cdot 4 \mathrm{~kb}$ HindIII-HinPI fragment.

\section{Strict host range of pCD3.4, and its modification by mutation in RepA}

To determine whether pCD3.4 can replicate in other organisms, plasmid pCD5 was used to transform a variety of bacterial strains. The erythromycin gene in pCD5 was inserted in such a way that it inactivated the divergicin operon by deleting the promoter region upstream of the divergicin A structural gene. Plasmid pCD5 could be transformed into C. maltaromaticum strains LV17C and UAL26, but transformants could not be obtained with $E$. coli MH1, Lc. lactis MG1363, Ent. faecalis ATCC 19433, Leu. gelidum UAL187-13 or Lb. casei ATCC 393. These results suggest that $\mathrm{pCD} 3.4$ has a narrow host range, and may only replicate in Carnobacterium spp.

Interestingly, after 2 days of incubation on APT agar plates, two erythromycin-resistant colonies were obtained when plasmid pCD5 was transformed into the plasmid-less strain Ent. faecium BFE900; both colonies harboured a pCD5-type plasmid. Transformation of BFE900 with the broad-hostrange plasmid pMG36e as a positive control yielded more than $10^{3}$ transformants $(\mu \mathrm{g} \mathrm{DNA})^{-1}$. These results indicate that although the two BFE900 colonies were genuine transformants, pCD5 cannot readily be transformed into BFE900. Plasmids extracted from the two transformants, named pCD51 and pCD52, were used to transform $C$. maltaromaticum UAL26. pCD5 was used as a positive control for transforming UAL26. More than $10^{4}$ transformants ( $\mu \mathrm{g}$ DNA $)^{-1}$ were obtained after transformation with 
pCD5, whereas no transformants were obtained with pCD51 and pCD52. When pCD51 and pCD52 were used to electroporate BFE900, more than $10^{3}$ transformants ( $\mu \mathrm{g}$ DNA $)^{-1}$ were obtained with both plasmids, but no transformants were observed after 2 days of incubation following electroporation with plasmid pCD5. These results demonstrate that plasmids pCD51 and pCD52 underwent changes that altered the host specificity of the pCD derivative. The replication region of both pCD51 and pCD52 was sequenced at the nucleotide level. No mutation was found in the region upstream of the RepA gene, including the DNA iterons and other sequences essential for replication of the pCD replicon. However, a single amino acid substitution was observed at position 232 inside the RepA protein encoded by pCD51 and pCD52. In both plasmids, the CCA codon for proline was changed into a TCA codon for serine. The fact that this mutation was identical in two separate Ent. faecium transformants most likely confirms that this change in RepA changed the host range of the pCD3.4 replicon. Attempts to transform Ent. faecalis ATCC 19433 with pCD51 and pCD52 were unsuccessful. Apparently, this amino acid substitution in the C-terminal part of the RepA protein enabled the plasmid to change its narrow host range for replication from $C$. maltaromaticum to Ent. faecium. Modulation of the host range of a plasmid by mutations in the replication protein has also been described for pPS10 of Pseudomonas savastanoi. Plasmid pPS10 cannot establish itself in E. coli at $37^{\circ} \mathrm{C}$, and replicates poorly in this host at $30^{\circ} \mathrm{C}$. However, mutations in RepA of pPS10 have been obtained that result in transformants of E. coli that grow at $37^{\circ} \mathrm{C}$ (FernándezTresguerres et al., 1995; Maestro et al., 2003). An enhanced interaction of the host-encoded DnaA protein with these mutant RepA proteins is observed (Maestro et al., 2003). Furthermore, pPS10 can also be established in E. coli by a chromosomal mutation of the $d n a A$ gene, giving further evidence that interaction between host-encoded DnaA and plasmid-encoded RepA influences the host range of pPS10 (Maestro et al., 2002). It is unclear whether such a mechanism is also responsible for the ability of the RepA(P232S) mutant of pCD3.4 to replicate in Ent. faecium and not in C. maltaromaticum. The change of the host range of pCD3.4 by this repA mutation might be explained by assuming that the RepA protein of pCD3.4 interacts in a similar manner with a host-encoded protein. This interaction could take place with the C-terminal domain of RepA, where the mutation is located; however, the possibility that the mutation induces a conformational change elsewhere in the Rep protein cannot be ruled out. The fact that a DnaA box was not found in pCD3.4 could indicate that other hostencoded proteins are involved in the interaction with RepA. It has been shown that plasmid replication proteins can interact with other host-encoded replication proteins, such as DnaB helicase and DnaG primase (Abhyankar et al., 2004; Datta et al., 1999; Jiang et al., 2003). The finding that pCD3.4 has a very narrow host range indicates that host factors may play a role in the host-range specificity of this plasmid. These results might form a basis to develop cloning vectors based on pCD3.4 that are tailored towards specific bacterial strains.

\section{ACKNOWLEDGEMENTS}

This work was supported by a strategic grant from the Natural Sciences and Engineering Council of Canada. We thank O. Kuipers, University of Groningen, Haren, The Netherlands, for supplying plasmids pGS30 and pUC7e. We also thank Randy Worobo and Vinita Vaz for technical assistance.

\section{REFERENCES}

Abeles, A. L., Snyder, K. M. \& Chattoraj, D. K. (1984). P1 plasmid replication: replicon structure. J Mol Biol 173, 307-324.

Abhyankar, M. M., Reddy, J. M., Sharma, R., Büllesbach, E. \& Bastia, D. (2004). Biochemical investigations of control of replication initiation of plasmid R6K. J Biol Chem 279, 6711-6719.

Ahn, C. \& Stiles, M. E. (1990). Plasmid-associated bacteriocin production by a strain of Carnobacterium piscicola from meat. Appl Environ Microbiol 56, 2503-2510.

Aubert, S., Dyke, K. G. \& Solh, N. E. (1998). Analysis of two Staphylococcus epidermidis plasmids coding for resistance to streptogramin A. Plasmid 40, 238-242.

Benachour, A., Frère, J. \& Novel, G. (1995). pUCL287 plasmid from Tetragenococcus halophilus (Pediococcus halophilus) ATCC 33315 represents a new theta-type replicon family of lactic acid bacteria. FEMS Microbiol Lett 128, 167-176.

Benachour, A., Frère, J., Flahaut, S., Novel, G. \& Auffray, Y. (1997). Molecular analysis of the replication region of the theta-replicating plasmid pUCL287 from Tetragenococcus (Pediococcus) halophilus ATCC 33315. Mol Gen Genet 255, 504-513.

Birnboim, H. C. \& Doly, J. (1979). A rapid alkaline extraction procedure for screening recombinant plasmid DNA. Nucleic Acids Res 7, 1513-1523.

Bruand, C., Le Chatelier, E., Ehrlich, S. D. \& Jannière, L. (1993). A fourth class of theta-replicating plasmids: the $\mathrm{pAM} \beta 1$ family from Gram-positive bacteria. Proc Natl Acad Sci U S A 90, 11668-11672.

Casadaban, M. J. \& Cohen, S. N. (1980). Analysis of gene control signals by DNA fusion and cloning in Escherichia coli. J Mol Biol 138, 179-207.

Churchward, G., Linder, P. \& Caro, L. (1983). The nucleotide sequence of replication and maintenance functions encoded by plasmid pSC101. Nucleic Acids Res 11, 5645-5659.

Datta, H. J., Khatri, G. S. \& Bastia, D. (1999). Mechanism of recruitment of DnaB helicase to the replication origin of the plasmid pSC101. Proc Natl Acad Sci U S A 96, 73-78.

De Man, J. C., Rogosa, M. \& Sharpe, M. E. (1960). A medium for the cultivation of lactobacilli. J Appl Bacteriol 23, 130-135.

Eguchi, T., Doi, K., Nishiyama, K., Ohmomo, S. \& Ogata, S. (2000). Characterization of a phage resistant plasmid, pLKS, of silagemaking Lactobacillus plantarum NGRI0101. Biosci Biotechnol Biochem 64, 751-756.

Fernández-Tresguerres, M. E., Martín, M., García de Viedma, D., Giraldo, R. \& Diaz-Orejas, R. (1995). Host growth temperature and a conservative amino acid substitution in the replication protein of pPS10 influence plasmid host range. J Bacteriol 177, 4377-4384.

Foley, S., Bron, S., Venema, G., Daly, C. \& Fitzgerald, G. F. (1996). Molecular analysis of the replication origin of the Lactococcus lactis plasmid pCI305. Plasmid 36, 125-141. 
Franz, C. M. A. P., Worobo, R. W., Quadri, L. E. N., Schillinger, U., Holzapfel, W. H., Vederas, J. C. \& Stiles, M. E. (1999). Atypical genetic locus associated with constitutive production of enterocin $\mathrm{B}$ by Enterococcus faecium BFE900. Appl Environ Microbiol 65, 21702178.

Frère, J., Novel, M. \& Novel, G. (1993). Molecular analysis of the Lactococcus lactis subspecies lactis CNRZ270 bidirectional theta replicating lactose plasmid pUCL22. Mol Microbiol 10, 1113-1124.

Fujimoto, S., Tomita, H., Wakamatsu, E., Tanimoto, K. \& Ike, Y. (1995). Physical mapping of the conjugative bacteriocin plasmid pPD1 of Enterococcus faecalis and identification of the determinant related to the pheromone response. J Bacteriol 177, 5574-5581.

Gasson, M. J. (1983). Plasmid complements of Streptococcus lactis NCDO712 and other lactic streptococci after protoplast-inducing curing. J Bacteriol 154, 1-9.

Hastings, J. W. \& Stiles, M. E. (1991). Antibiosis of Leuconostoc gelidum isolated from meat. J Appl Bacteriol 70, 127-134.

Hayes, F., Vos, P., Fitzgerald, G. F., de Vos, W. M. \& Daly, C. (1991). Molecular organization of the minimal replicon of novel, narrowhost-range, lactococcal plasmid pCI305. Plasmid 25, 16-26.

Hedberg, P. J., Leonard, B. A., Ruhfel, R. E. \& Dunny, G. M. (1996). Identification and characterization of the genes of Enterococcus faecalis plasmid pCF10 involved in replication and in negative control of pheromone-inducible conjugation. Plasmid 35, 46-57.

Holo, H. \& Nes, I. F. (1989). High-frequency transformation, by electroporation, of Lactococcus lactis subsp. cremoris grown in glycine in osmotically stabilized media. Appl Environ Microbiol 173, 38793887.

Jiang, Y., Pacek, M., Helinski, D. R., Konieczny, I. \& Toukdarian, A. (2003). A multifunctional plasmid-encoded replication initiation protein both recruits and positions active helicase at the replication origin. Proc Natl Acad Sci U S A 100, 8692-8697.

Kanatani, K., Tahara, T., Oshimura, M., Sano, K. \& Umezawa, C. (1995). Identification of the replication region of Lactobacillus acidophilus plasmid pLA103. FEMS Microbiol Lett 133, 127-130.

Kearney, K., Fitzgerald, G. F. \& Seegers, J. F. M. L. (2000). Identification and characterization of an active plasmid partition mechanism for the novel Lactococcus lactis plasmid pCI2000. J Bacteriol 182, 30-37.

Kiewiet, R., Bron, S., de Jonge, K., Venema, G. \& Seegers, J. F. M. L. (1993a). Theta replication of the lactococcal plasmid pWVO2. Mol Microbiol 10, 319-327.

Kiewiet, R., Kok, J., Seegers, J. F. M. L., Venema, G. \& Bron, S. (1993b). The mode of replication is a major factor in segregational plasmid instability in Lactococcus lactis. Appl Environ Microbiol 59, 358-364.

Kim, Y.-J. \& Meyer, R. J. (1991). An essential iteron-binding protein required for plasmid R1162 replication induces localized melting within the origin at a specific site in AT-rich DNA. J Bacteriol 173, 5539-5545.

Le Chatelier, E., Ehrlich, S. D. \& Jannière, L. (1993). Biochemical and genetic analysis of the unidirectional theta replication of the $S$. agalactiae plasmid pIP501. Plasmid 29, 50-56.

Leenhouts, K. J., Tolner, B., Bron, S., Kok, J., Venema, G. \& Seegers, J. F. M. L. (1991). Nucleotide sequence and characterization of the broad-host-range lactococcal plasmid pWVO1. Plasmid 26, $55-66$.

Maestro, B., Sanz, J. M., Faelen, M., Couturier, M., Díaz-Orejas, R. \& Fernández-Tresguerres, E. (2002). Modulation of pPS10 host range by DnaA. Mol Microbiol 46, 223-234.
Maestro, B., Sanz, J. M., Díaz-Orejas, R. \& Fernández-Tresguerres, E. (2003). Modulation of pPS10 host range by plasmid-encoded RepA initiator protein. J Bacteriol 185, 1367-1375.

Mandel, M. \& Higa, A. (1970). Calcium dependent bacteriophage DNA infection. J Mol Biol 53, 159-162.

Martínez-Bueno, M., Valdivia, E., Gálvez, A. \& Maqueda, M. (2000). pS86, a new theta-replicating plasmid from Enterococcus faecalis. Curr Microbiol 41, 257-261.

Meijer, W. J. J., de Boer, A. J., van Tongeren, S., Venema, G. \& Bron, S. (1995). Characterization of the replication region of the Bacillus subtilis plasmid pLS20: a novel type of replicon. Nucleic Acids Res 23 , 3214-3223.

Pal, S. K., Mason, R. J. \& Chattoraj, D. K. (1986). P1 plasmid replication. Role of initiator titration in copy number control. $J \mathrm{Mol}$ Biol 192, 275-285.

Rotlander, E. \& Trautner, T. A. (1970). Genetic and transfection studies with Bacillus subtilis phage SP50. J Mol Biol 108, 47-60.

Sambrook, J., Fritsch, E. F. \& Maniatis, T. (1989). Molecular Cloning: a Laboratory Manual, 2nd edn. Cold Spring Harbor, NY: Cold Spring Harbor Laboratory.

Sanger, F., Nicklen, S. \& Coulson, A. R. (1977). DNA sequencing with chain-terminating inhibitors. Proc Natl Acad Sci U S A 74, 5463-5467.

Sørvig, E., Skaugen, M., Naterstad, K., Eijsink, V. G. \& Axelsson, L. (2005). Plasmid p256 from Lactobacillus plantarum represents a new type of replicon in lactic acid bacteria, and contains a toxinantitoxin-like plasmid maintenance system. Microbiology 151, 421-431.

Studier, F. W. \& Moffat, B. (1986). Use of bacteriophage T7 RNA polymerase to direct selective high expression of cloned genes. $J \mathrm{Mol}$ Biol 189, 113-130.

Tabor, S. \& Richardson, C. C. (1985). A bacteriophage T7 RNA polymerase promoter system for controlled exclusive expression of specific genes. Proc Natl Acad Sci U S A 82, 1074-1078.

Tanaka, T. \& Ogura, M. (1998). A novel Bacillus natto plasmid pLS32 capable of replication in Bacillus subtilis. FEBS Lett 422, 243-246.

Terzaghi, B. E. \& Sandine, W. E. (1975). Improved medium for lactic streptococci and their bacteriophages. Appl Microbiol 29, 807-813.

van Belkum, M. J. \& Stiles, M. E. (1995). Molecular characterization of genes involved in the production of the bacteriocin leucocin A from Leuconostoc gelidum. Appl Environ Microbiol 61, 3573-3579.

van Belkum, M. J., Worobo, R. W. \& Stiles, M. E. (1997). Doubleglycine-type leader peptides direct secretion of bacteriocins by $\mathrm{ABC}$ transporters: colicin V secretion in Lactococcus lactis. Mol Microbiol 23, 1293-1301.

van de Guchte, M., van der Vossen, J. M. B. M., Kok, J. \& Venema, G. (1989). Construction of a lactococcal expression vector: expression of hen egg white lysozyme in Lactococcus lactis subsp. lactis. Appl Environ Microbiol 55, 224-228.

Vieira, J. \& Messing, J. (1987). Production of single-stranded plasmid DNA. Methods Enzymol 153, 3-11.

Weaver, K. E., Clewell, D. B. \& An, F. (1993). Identification, characterization, and nucleotide sequence of a region of Enterococcus faecalis pheromone-responsive plasmid pAD1 capable of autonomous replication. J Bacteriol 175, 1900-1909.

Worobo, R. W., van Belkum, M. J., Sailer, M., Roy, K. L., Vederas, J. C. \& Stiles, M. E. (1995). A signal peptide secretion-dependent bacteriocin from Carnobacterium divergens. J Bacteriol 177, 3143-3149. 